23

\title{
Исследование состава пигментов на поверхности женской статуэтки с палеолитической стоянки Костенки 1 методом инфракрасной спектроскопии отражения
}

\author{
(C) В.М. Золотарев ${ }^{1}$, Г.А. Хлопачев ${ }^{2}$ \\ ${ }^{1}$ Университкт ИТМО, \\ 197101 Санкт-Петербург, Россия \\ ${ }^{2}$ Музей антропологии и этнографии им. Петра Великого (Кунсткамера) РАН, \\ 199034 Санкт-Петербург, Россия \\ e-mail: vm-zolotarev@mail.ru
}

Поступила в редакцию 27.01.2020 г.

В окончательной редакции 27.01.2020 г.

Принята к публикации 06.02.2020 г.

Методом ИК спектроскопии отражения исследован структурно-химический состав окрашенного слоя, находящегося на поверхности женской статуэтки из бивня мамонта с восточно-граветтийской стоянки Костенки 1, слой I, возраст 23-21 тысяча лет. Стоянка расположена на территории села Костенки в Хохольском районе Воронежской области России. Статуэтка находилась на дне ямки-хранилища с остатками краски красного цвета. Слой краски на фигурке состоит из глинозема и гипса, красящие пигменты - по преимуществу оксиды железа. Полученные данные позволяют предположить, что технология, использованная палеолитическим художником при окрашивании статуэтки палеолитической Венеры, включала этап предварительной подготовки поверхности - грунтовки обработанной поверхности с использованием гипса.

Ключевые слова: пигменты окраски палеолитических статуэток, аналитическая ИК спектроскопия отражения, нейронные сети.

DOI: $10.21883 /$ OS.2020.05.49330.24-20

\section{Введение}

В настоящее время изучение состава пигментов, входивших в состав древнейших красок, является одним из активно развивающихся направлений исследований в современном палеолитоведении. Хорошо известны работы по определению пигментов различных красок, которые применялись как для нанесения изображений на скальные поверхности пещер и гротов [1,2], так и для раскрашивания резного декора на предметах искусства малых форм [3]. Применительно к материалам Восточной Европы большой резонанс получила гипотеза Н.Д. Праслова об использовании красной краски для окрашивания верхнепалеолитических женских статуэток из известняка, а черной краски - для окрашивания подобных фигурок из бивня мамонта [4]. Сложность подтверждения этой гипотезы заключается в том, что красная краска диагностируется на предметах из культурного слоя сравнительно легко, а черная краска имеет большое внешнее сходство с целым рядом природных образований. Например, черную краску легко спутать с черной пленкой двуокиси марганца, выпадающей на костях в процессе фильтрации жидких растворов солей, сопровождающих почвообразование [4]. Самой известной женской фигуркой со следами черной окрашенности на поверхности является крупная бивневая статуэтка из первого жилого комплекса верхнепалеолитической стоянки Костенки 1 (слой 1), ее возраст 23-21 тысяча лет. Фигурка выполнена в яркой реалистичной манере и передает образ обнаженной, представленной в полный рост женщины. Статуэтка найдена в ходе раскопок П.П. Ефименко в 1931 г. на дне ямки-хранилища овальной формы $1.05 \times 0.76 \mathrm{~m}$ и глубиной $0.35-0.40 \mathrm{~m}$. В этой ямке обычное заполнение в виде „культурного слоя“ отсутствовало, а ее дно „было окрашено в красный цвет благодаря присутствию охры“ [5]. Пятна красной краски были диагностированы как наличие в яме-хранилище „обычной железистой краски“, что могло объяснять присутствие пятен красной краски на поверхности другой, находившейся рядом и разбитой в древности женской фигурки из известняка [5]. Что касается бивневой статуэтки, то автор находки отмечал, что она при извлечении из слоя имела иную - темно-коричневатую патину [5]. В настоящее время данная окрашенность сохранилась на различных участках статуэтки, где окрашенность была наиболее плотной и интенсивной. Здесь она имела плотный темно-вишневый цвет со стальным отливом. На других участках окрашенность сохранилась только фрагментарно.

Цель настоящего исследования состояла в изучении химического состава пигментов на разных участках поверхности бивневой статуэтки бесконтактным неразрушающим методом ИК спектроскопии отражения.

\section{Морфология поверхности объекта}

Для сравнения на рис. 1 представлены две женские палеолитические статуэтки, изготовленные из бивня 


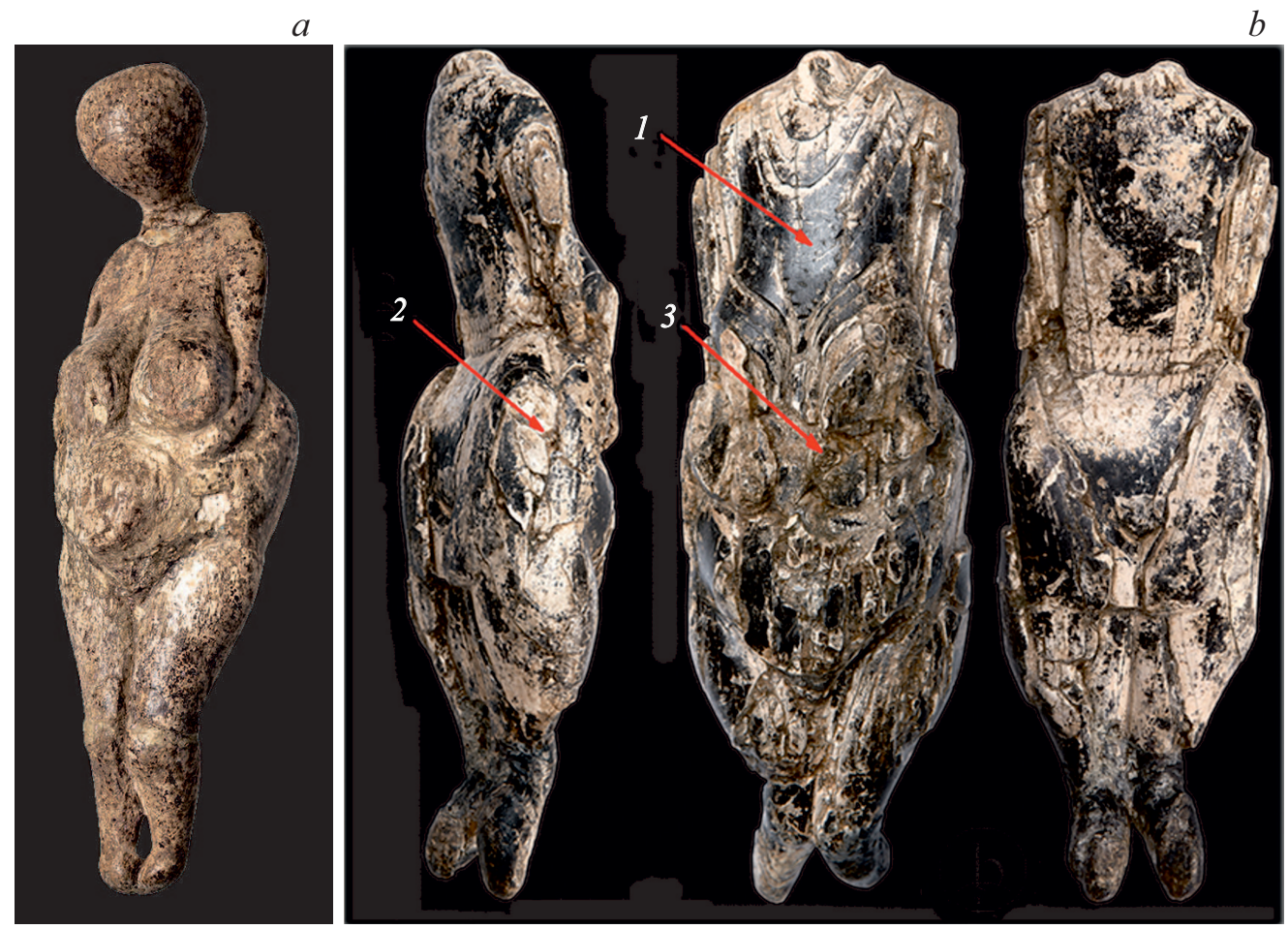

Рис. 1. Фото двух женских статуэток, выполненных по костенковскому канону, со стоянки Костенки 1, слой I (Воронежская обл., Россия): $a$ - целая фигурка, находка 1936 г. (МАЭ 6051-2) [6,7], $b$ - исследуемая фигурка, находка 1931 г. (голова утрачена в древности) (МАЭ 6051-1) [7]. Стрелками показаны зоны 1, 2 и 3 соответственно.

мамонта. Слева (рис. 1,a) показана целая статуэтка [6,7] без следов окраски, справа - исследуемая однотипная статуэтка со следами окрашивания (рис. 1,b). Заготовкой для изготовления последней послужил отщеп, сколотый с поверхности бивня мамонта без цементного слоя на наружной поверхности. Таким образом, исследуемая статуэтка образована дентином, состоящим на $\approx 75 \%$ из апатита $\mathrm{Ca}_{5}\left(\mathrm{PO}_{4}\right)^{3}(\mathrm{~F}, \mathrm{OH}, \mathrm{Cl})$, остальные $\approx 25 \%$ приходятся на органику и воду. На поверхности фигуры (рис. 1,b) можно выделить три характерные области: окрашенные участки, которые имеют темновишневый цвет (зона 1), участки без окраски (зона 2) и частично окрашенные (зона 3 ). Изучение этих участков под оптическим микроскопом показало, что окрашенная поверхность зоны 1 гладкая, тогда как поверхность светлой зоны 2 шероховатая, шероховатость поверхности зона 3 - промежуточная между зонами 1 и 2. Важно отметить, что исследуемая фигура Венеры палеолита ранее подвергалась консервации путем нанесения защитной полимерной пленки, что видно из последующих спектроскопических исследований $[8,9]$.

\section{Методика исследований и оптическая модель зон объекта}

Исследования костенковской статуэтки проводились бесконтактным неразрушающим методом ИК спектроскопии отражения. Попытка использовать для исследова- ния метод комбинационного рассеяния (спектрометр КР с микроскопом - модель inVia confocal Raman фирмы Renishaw, спектр КР возбуждался Не-Ne-лазером) не дала ожидаемых результатов из-за сильной фотолюминесценции, что объясняется наличием на поверхности статуэтки консервационной полимерной пленки.

Учитывая существенные различия в отражательных свойствах поверхности объекта (не плоская геометрия поверхности и ее шероховатость), что приводило к существенному снижению измеряемого сигнала, были выбраны следующие режимы работы ИК фурье-спектрофотометра ALPHA фирмы Bruker: диаметр диафрагмы $6 \mathrm{~mm}$, разрешение $4 \mathrm{~cm}^{-1}, 500$ сканов. Классификация измеренных ИК спектров (рис. 2) проводилась с использованием баз данных (BD) ИК спектров неорганических веществ и полимеров: BD спектров абсорбции [10], $\mathrm{BD}$ спектров абсорбции пигментов [11], BD спектров диффузного отражения [12], BD спектров зеркального отражения [13]. Алгоритм поиска опирался на задаваемые оператором формы спектров и частоты наиболее интенсивных ИК полос поглощения пигментов, которые могли использоваться в древние времена. Эти сведения получены на основе информации об известных месторождениях минералов того региона, в котором был обнаружен исследуемый артефакт [6,7]. С учетом проведенной классификации по форме экспериментальных спектров установлено (рис. 2), что для зоны 1 характерен ИК спектр зеркального отражения, для зоны 2 - ИК спектр 


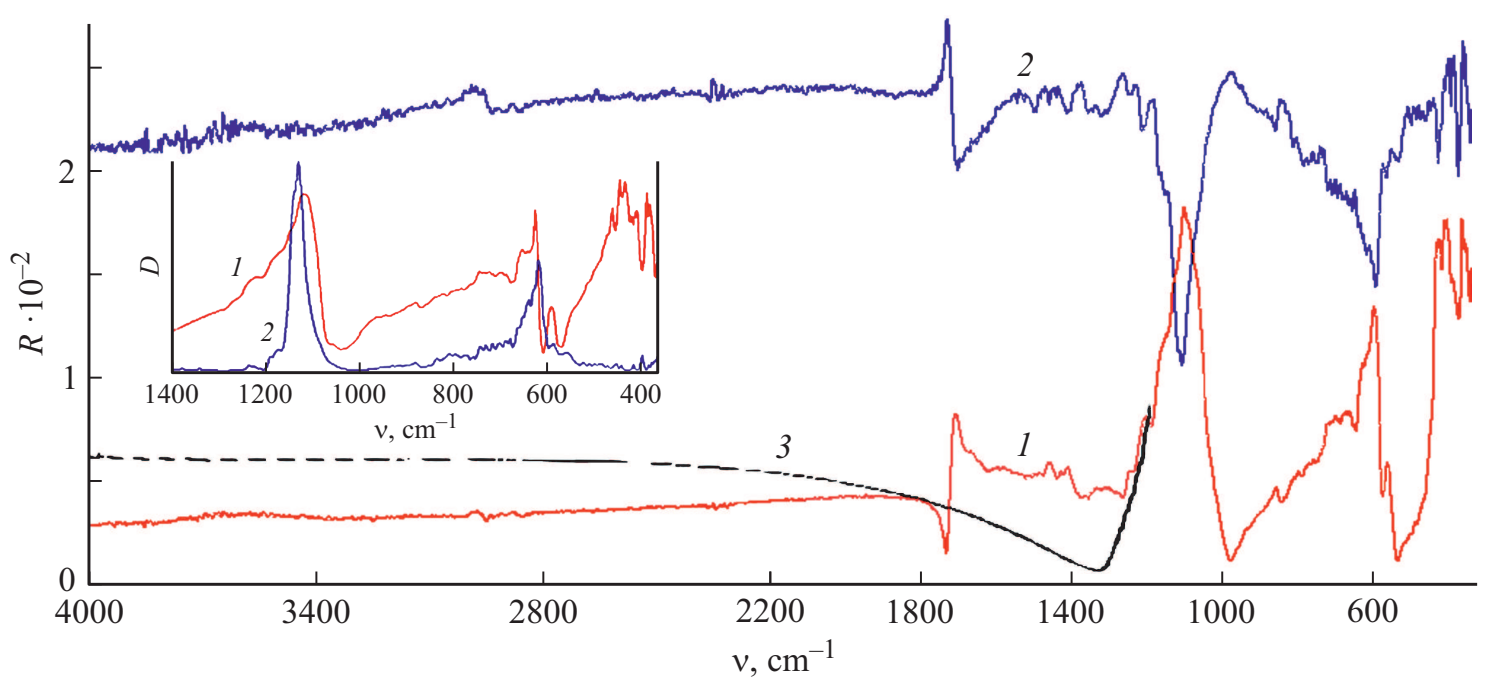

Рис. 2. Экспериментальные спектры отражения $R$ двух участков исследуемой статуэтки: $1-$ зона $1,2-$ зона 2 (кривая 2 смещена вверх), 3 - диапазон 4000-900 $\mathrm{cm}^{-1}$ спектра 1 после коррекции. На вставке показаны результаты расчета оптической плотности $D$ (relative units) вычисленные для зоны 1 (метод Крамерса-Кронига) и зоны 2 (метод Кубелки-Мунка).

диффузного отражения. Инфракрасный спектр зоны 3 носил промежуточный характер между спектрами зон 1 и 2. Коррекция исходного (экспериментального) ИК спектра отражения от зоны 1 проводилась по технологии сверточных нейронных сетей [14-17]. Исходный спектр (рис. 2, кривая 1) в области $4000-2000 \mathrm{~cm}^{-1}$ предварительно корректировался в ближней ИК области по амплитуде с учетом ориентировочного долевого состава (глинозем+пигмент) окрашенного слоя. Поскольку основой пигментного слоя является вяжущий глинозем, значение $R$ для этого диапазона определялось в первом приближении на основе значения показателя преломления $n_{D}$ глинозема [18]. После первого этапа корректировки спектра, проводилась коррекция значений коэффициента отражения в области между основными полосами отражения. Эта коррекция опиралась на процедуру сопоставления формы и интенсивности основных полос исходного ИК спектра отражения с результатами расчета спектра с подобными параметрами, который выполнялся методом классического дисперсионного анализа [19]. После второго этапа корректировки спектр (рис. 2, кривая 2) достраивался в диапазоне $400-100 \mathrm{~cm}^{-1}$ путем использования для этого диапазона данных [10] и последующей экстраполяции спектра $R$ в область более низких частот по стандартной процедуре OPUS 7. После чего откорректированный спектр $R$ обрабатывался с помощью метода Крамерса-Кронига [19]. Таким образом, из исходного ИК спектра $R$ получали спектры оптической плотности $D$ или оптических постоянных $n$ и $k$. Спектр показателя поглощения $k$ приведен на рис. 3, кривая 3, и сопоставлен затем с литературными данными для основных ИК полос абсорбции минералов-пигментов [20-24].

Полученные данные позволяют сформировать оптическую модель объекта исследования, которая отличается для зон 1 и 2. Для зоны 1 оптическая модель поверхности объекта может быть представлена в виде следующей системы слоев: пленка полимера (толщина $\left.d_{1}\right)$ слой вещества неорганического происхождения (толщина $\left.d_{2}\right)$ - основание (подложка из дентина-бивня мамонта, d3). Судя по классическому виду формы полосы отражения полимерной пленки $1730 \mathrm{~cm}^{-1}$, поверхность в окрестности зоны 1 гладкая, а толщина консервационной пленки $d_{1} \geq \lambda \approx 7 \mu \mathrm{m}$. Исходя из использованного критерия для зон 2 и 3 толщина слоя $d_{1} \geq \lambda$. Из анализа формы полосы $450 \mathrm{~cm}^{-1}$ (рис. 2, кривая 1) глинозема следует, что толщина слоя $d_{2} \geq \lambda \approx 22 \mu \mathrm{m}$, в результате подложка не проявляется в измеряемом спектре $R$. При этом вид ИК спектра отражения зоны 1 указывает, что слой $d_{2}$ не плоский и имеет микрорельеф. Эти особенности слоя $d_{2}$ приводят к общему ослаблению измеряемого сигнала (рис. 2, кривая 1), который к тому же имеет спектральную зависимость, обусловленную рассеянием. Это наглядно проявляется в поведении спектра в области $4000-1800 \mathrm{~cm}^{-1}$, и особенно в повышении коэффициента отражения $R$ в окрестности минимума с высокочастотной стороны полосы у $1124 \mathrm{~cm}^{-1}$. Неточное (завышенное) значение измеряемой величины $R$ в окрестности минимума интенсивных полос с высокочастотной стороны весьма критично для расчетов показателя поглощения $k$ с использованием соотношений Крамерса-Кронига [25].

Оптическую модель зоны 2 можно представить в виде шероховатой поверхности (среднеквадратичная высота шероховатостей $d>\lambda \approx 7 \mu \mathrm{m}$ ), где впадины частично заполнены остатками вещества неорганического происхождения. Поверхность зоны 2, так же как и зоны 1 , закрыта консервационной полимерной пленкой. Такая система строения поверхности создает хорошие условия для диффузного отражения ИК излучения в средней ИК 


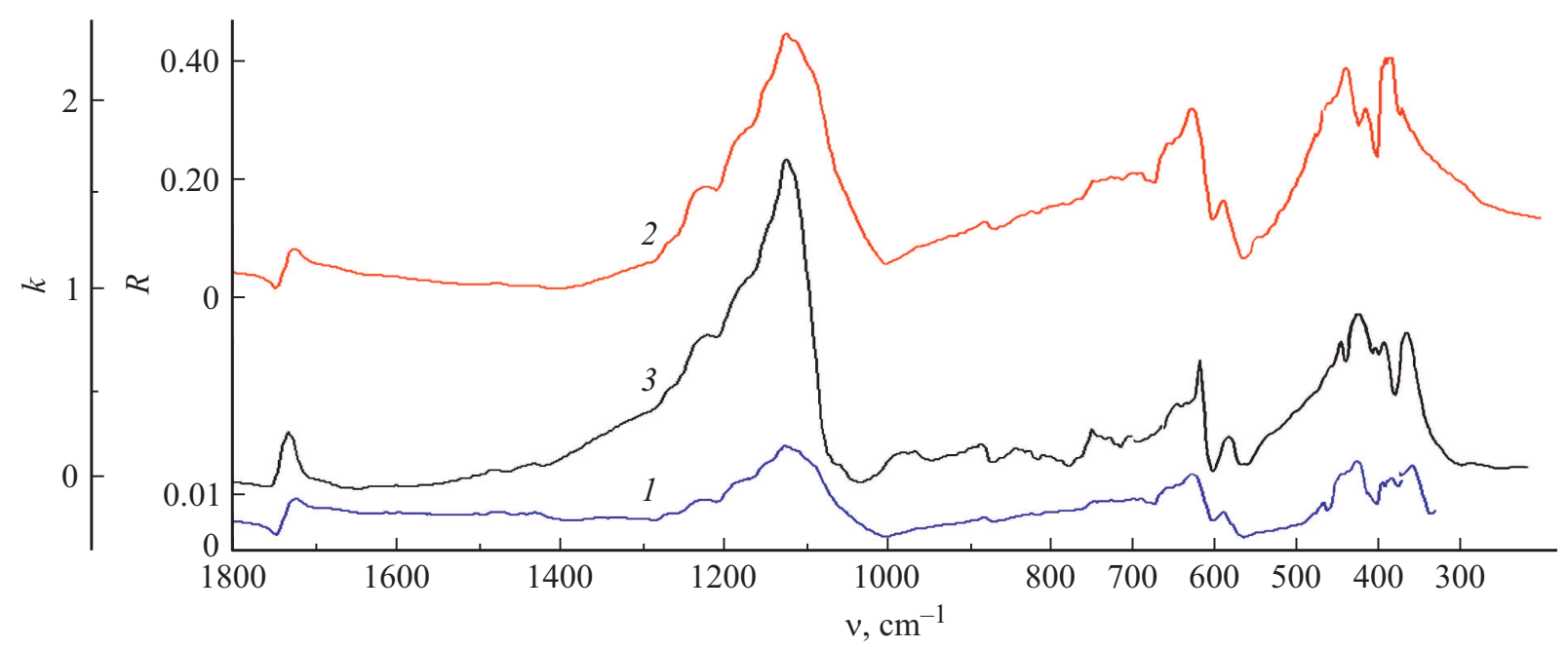

Рис. 3. Спектры коэффициента отражения $R$ и показателя поглощения $k$ зоны $1: 1$ - исходный экспериментальный спектр (нижняя шкала $R$ ); 2 - спектр после коррекции величины $R$ и экстраполяции к низким частотам(верхняя шкала $R) ; 3-$ показатель поглощения $k$, вычисленный из спектра 2 методом Крамерса-Кронига.

области спектра, что обеспечивает выполнение соотношения Кубелки-Мунка [19]. В результате реализуется пропорциональная зависимость между измеряемой величиной диффузного отражения и концентрацией вещества, находящегося в углублениях между шероховатостями [26-28]. Следует отметить, что в длинноволновой области ИК спектра размер шероховатостей $d$ для зоны 2 становится сопоставим с длиной волны $\lambda$, в результате чего контрастность таких полос (например, полоса $450 \mathrm{~cm}^{-1}$ ) уменьшается (рис. 2, кривая 2). Этот эффект обусловлен нарушением глубинного режима рассеяния для больших длин волн, поскольку с ростом длины волны отношение $\lambda / d$ возрастает. Вместе с тем для этой области спектра оптические характеристики краски, состоящей из глинозема и пигментов, имеют большие значения коэффициента поглощения $k[11,20]$. В результате с ростом $\lambda$ усиливается вклад зеркальной компоненты $R$ в измеряемый сигнал и как следствие возникает отступление от условий, необходимых для выполнения соотношения Кубелки-Мунка. Уменьшение контраста полосы $450 \mathrm{~cm}^{-1}$ в спектре зоны 2 хорошо видно из сопоставления спектров зон 1 и 2 (рис. 2). По этой причине на рис. 4 для зоны 2 не приводится спектр в диапазоне $550-400 \mathrm{~cm}^{-1}$. Отмеченная особенность спектров зон 1 и 2 дает дополнительные аргументы в пользу того, что для зоны 1 толщина слоя $d_{2} \gg \lambda$, т.е. отражение в данном случае реализуется от массивной среды. При этом, как и в случае зоны 1 , для зоны 2 подложка из дентина оказывает слабое влияние на результирующий спектр $R$.

\section{Результаты}

В спектрах зон 1 и 2 (рис. 2 и 3) наблюдаются полосы 2952, 1730, 1426, 1272, 1229, 1185, 1170, 943, 810,
$732 \mathrm{~cm}^{-1}$, которые принадлежат полимерной пленке, что позволяют отнести их к консервационному покрытию на основе сополимера метакриловой кислоты: бутилметакрилата и метакриловой кислоты (БМК-5) или сополимера полиметилметакрилата (ПММА) [19,29]. В частности, интенсивность характерного пика поглощения группы $\mathrm{C}=\mathrm{O}$ у $1730 \mathrm{~cm}^{-1}$ (имеется в спектрах ПММА и БМК-5), полученная расчетом для зоны 1 (рис. 3, кривая 3) с учетом коррекции величины $R$ по описанной выше методике, соответствует литературным данным для показателя поглощения $(k=0.44)$ ПММА $[19,30]$, для БМК-5 таких данных нет.

Спектры зон 1 и 2 имеют инверсный характер, (рис. 2), что объясняется различием микрорельефа поверхности этих зон. Разные отражательные свойства локальных участков поверхности древних археологических объектов отмечены также в работе [31], в которой методом ИК спектроскопии отражения исследовались костные останки человека.

В исследованной статуэтке зона 1 не плоская, но гладкая, и окрашенный слой $d_{2}$ достаточно толстый по сравнению с длиной волны зондирующего излучения (случай зеркального отражения, рис. 2, кривая 1), следовательно, полосы подложки $d_{3}$ (дентин) не будут проявляться в ИК спектре зоны 1 для области, где слой $d_{2}$ поглощает. Зона 2 не плоская и шероховатая, в результате наблюдается тип спектра (рис. 2, кривая 2), характерный для диффузного рассеяния с глубинным режимом поглощения веществ (для ИК диапазона $\approx 4000-600 \mathrm{~cm}^{-1}$ ), находящихся между выступами микрорельефа зоны 2 . Таким образом, инверсный характер спектров для зон 1 и 2 показывает, что внутри не окрашенной белой шероховатой зоны 2 тем не менее имеются отдельные, хотя и менее интенсивные ИК частоты колебаний, характерные для зоны 1. Например, к таким частотам принадлежат 


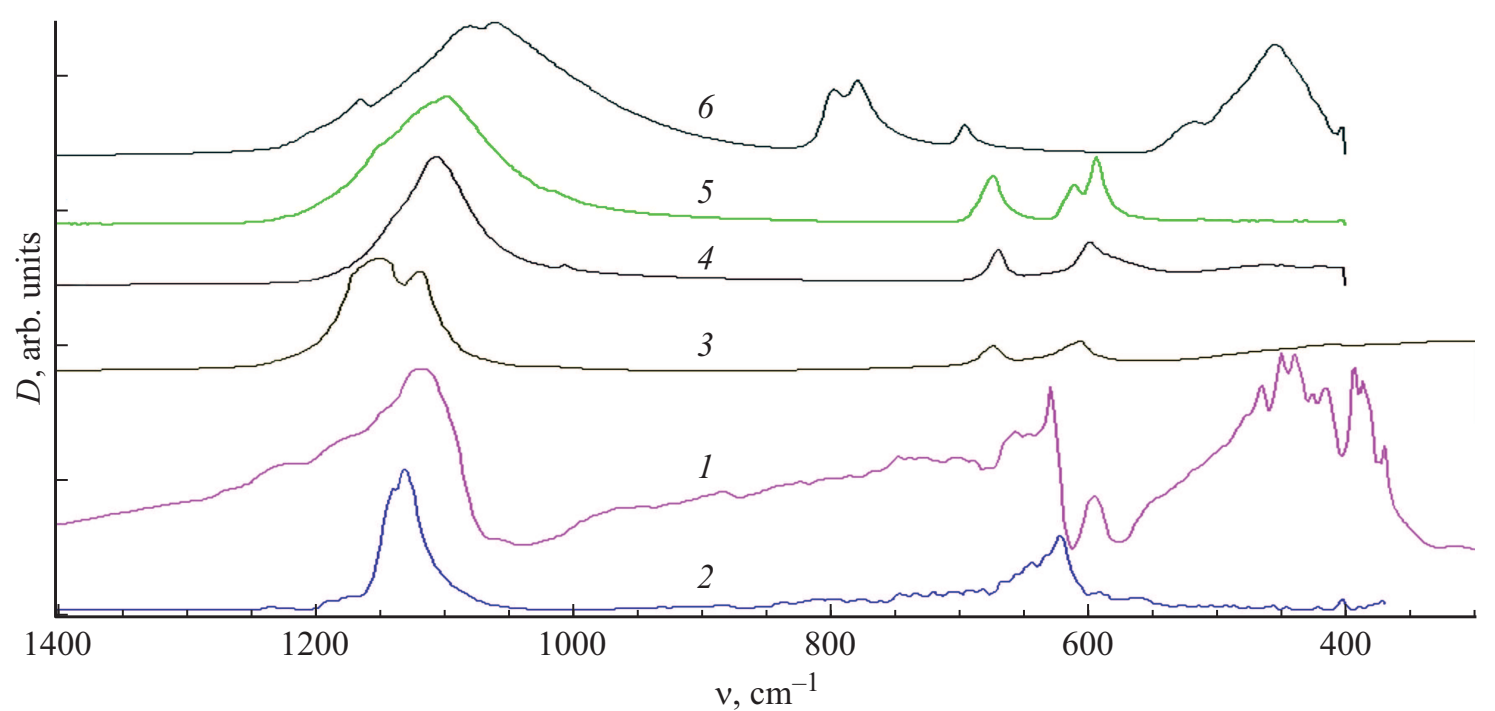

Pис. 4. Спектры поглощения (оптической плотности $D$ ) двух участков исследуемой статуэтки $(1-$ зона $1,2-$ зона 2$)$ в сопоставлении со спектрами поглощения гипса (3) [51] и спектрами нарушенного полного внутреннего отражения (Attenuated total reflection, ATR) гипса (4) [10], ангидрита (5) [10], кварца (6) [10]).

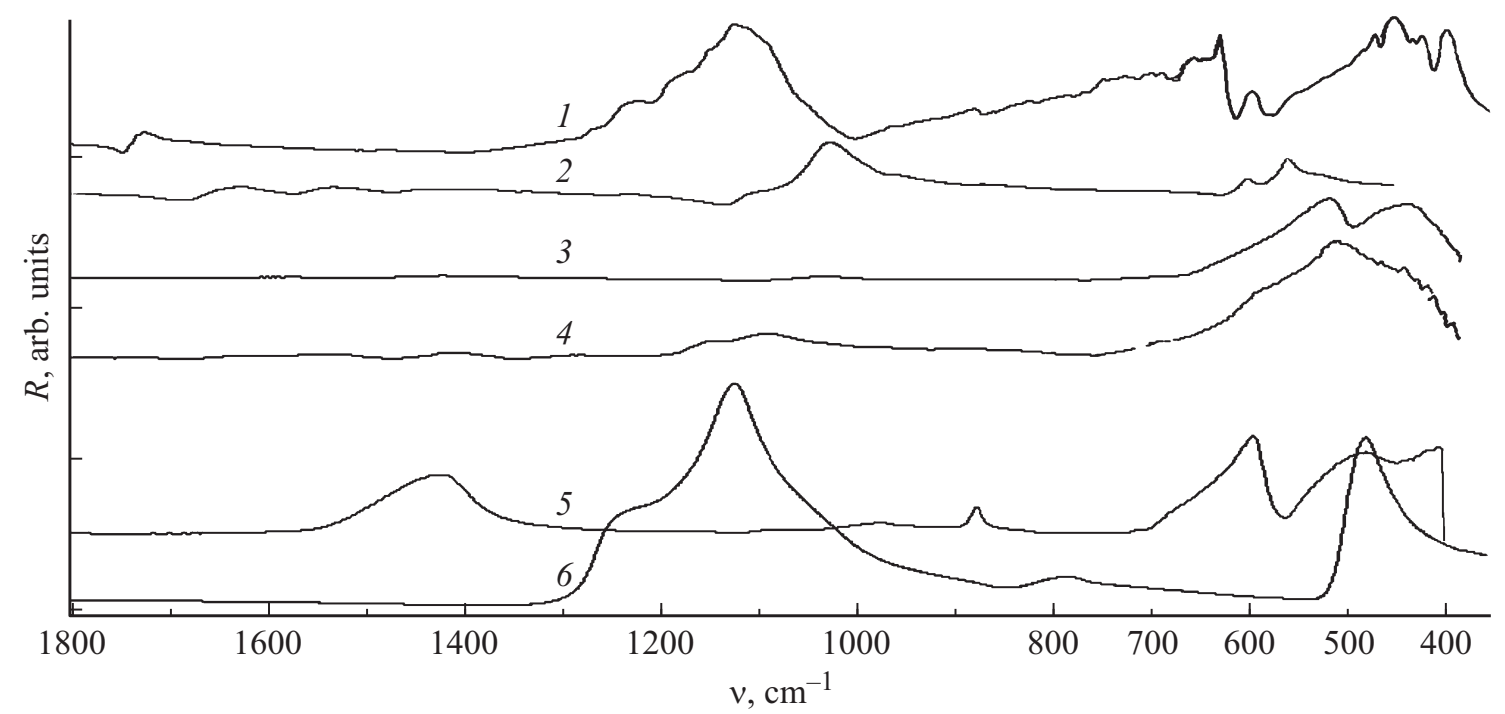

Рис. 5. Спектры отражения зоны 1 в сопоставлении со спектрами дентина, кварца и минералов, содержащих окислы Fe и Mn: 1 зона 1, 2-дентин бивня мамонта [27,28], $3-\mathrm{Fe}_{2} \mathrm{O}_{3}$ (Hematite) [10], $4-\mathrm{MnO}_{2}$ (Pyrolusite) [10], $5-\mathrm{Mn}_{3} \mathrm{O}_{4}$ (Hausmannite) [10], 6 __ $\mathrm{SiO}_{2}$ silica (плавленый кварц ) $[19,25]$. Для кривых 1, 2 и 6 соблюден масштаб величины $R$.

полосы 1138, 672, $606 \mathrm{~cm}^{-1}$, которые относятся к группе $\mathrm{O}-\mathrm{S}-\mathrm{O}$ ангидрида $\left(\mathrm{CaSO}_{4}\right)$ или гипса - водного сульфата кальция $\left(\mathrm{CaSO}_{4} \cdot 2 \mathrm{H}_{2} \mathrm{O}\right)$ (рис. 4) [10]. Высокая контрастность спектра 2 связана с более высокой чувствительностью режима получения ИК спектра, который реализуется для зоны 2 по сравнению с зоной 1 [26-28].

Полосы в районе 1222 (плечо), 1117 и $440 \mathrm{~cm}^{-1}$ в спектре оптической плотности $D$ для зоны 1 (рис. 4, кривая 1) относятся к группе $\mathrm{O}-\mathrm{Si}-\mathrm{O}$ глинозема $\left(\mathrm{Al}_{2}\left[\mathrm{Si}_{2} \mathrm{O}_{5}\right][\mathrm{OH}]_{4}\right)$ [18]. Смещение и уширение полосы $1100 \mathrm{~cm}^{-1}$, характерной для группы $\mathrm{O}-\mathrm{Si}-\mathrm{O}$ чистого $\left(\mathrm{SiO}_{2}\right)$ (рис. 4, кривая 6), относительно полосы глинозема $1117 \mathrm{~cm}^{-1}$ связано с особенностями метода ATR $[4,19]$, а также с химическим составом глинозема и добавками к массе глинозема порошка гипса (кривая 3) или ангидрида (кривая 5) в процессе приготовления краски $[10,11]$. Для спектра зоны 2, которая имеет белую окраску, наблюдается смещение полосы на $16 \mathrm{~cm}^{-1}$ и сужение более чем в 2 раза по сравнению с центром полосы $1117 \mathrm{~cm}^{-1}$ для зоны 1 (рис. 4), что может быть связано со снижением содержания вяжущего компонента (глинозема) краски в зоне 2 и тем самым более высокой концентрацией частиц гипса в поверхностном слое этой зоны. Полученные результаты дают основание 
Частоты основных ИК полос оксидов Fе и Mn, Fe-фосфатов и Fе-сульфатов

\begin{tabular}{|c|c|c|}
\hline Минералы, формула & Частоты, $\mathrm{cm}^{-1}$ & Источник \\
\hline$\alpha-\mathrm{Fe}_{2} \mathrm{O}_{3}$ hematite & $\begin{array}{c}575,485,385,360 \\
544,471,344\end{array}$ & $\begin{array}{l}{[44]} \\
{[51]}\end{array}$ \\
\hline $\begin{array}{c}\gamma-\mathrm{Fe}_{2} \mathrm{O}_{3} \text { maghemite } \\
\mathrm{Fe}_{3} \mathrm{O}_{4} \text { magnetite }\end{array}$ & $\begin{array}{c}693,639,565,455 \\
565,360 \\
1145,546\end{array}$ & $\begin{array}{l}{[23]} \\
{[44]} \\
{[10]}\end{array}$ \\
\hline $\mathrm{MNS}-\mathrm{Fe}_{3} \mathrm{O}_{4}$ & $1221,1184,651$ & {$[43]$} \\
\hline $\mathrm{MnO}_{2}$ pyrolusite & $\begin{array}{c}660-620,592,545,502,444,388 \\
580,510,440\end{array}$ & $\begin{array}{l}{[49]} \\
{[10]}\end{array}$ \\
\hline $\mathrm{Mn}_{3} \mathrm{O}_{4}$ hausmannite & $\begin{array}{l}1220,820,753,635,535 \\
1422,876,710,596,480\end{array}$ & $\begin{array}{l}{[50]} \\
{[10]}\end{array}$ \\
\hline $\mathrm{CaMn}_{2}+3 \mathrm{Mn}_{2+}\left(\mathrm{Si}_{5} \mathrm{O}_{15}\right)$ rhodonite & $1050,1018,946,889,718,664,562,490,452$ & {$[10]$} \\
\hline $\mathrm{FePO}_{4}$ & $1069,1035,690,665,575$ & {$[24]$} \\
\hline $\mathrm{FePO}_{4} \cdot 2 \mathrm{H}_{2} \mathrm{O}$ & $1155,1046,1103,880,640,576,553,337,285$ & {$[46]$} \\
\hline $\mathrm{FePO}_{4} \cdot 4 \mathrm{H}_{2} \mathrm{O}$ & $1094,990,715,593,552$ & {$[46]$} \\
\hline $\mathrm{NaFePO}_{4}$ & $1066,1014,950,700,628,585,533,464$ & {$[45]$} \\
\hline $\mathrm{FeSO}_{4}$ & $1284,1179,578$ & {$[45]$} \\
\hline $\begin{array}{c}\mathrm{FeSO}_{4} \cdot 2 \mathrm{H}_{2} \mathrm{O} \\
\mathrm{Fe}_{2}\left(\mathrm{SO}_{4}\right)_{3} \cdot 5 \mathrm{H}_{2} \mathrm{O}\end{array}$ & $\begin{array}{c}1184,1136,1049,654 \\
1193,1106,1053,1033\end{array}$ & $\begin{array}{l}{[45]} \\
{[48]}\end{array}$ \\
\hline $\mathrm{NaFeSO}_{4}$ & $1258,1100,997,688,595$ & {$[45]$} \\
\hline M-amorphous $\mathrm{Fe}^{3+}$ sulfate & $1200,1100,1140,1120,580,440,240$ & {$[45]$} \\
\hline $\mathrm{Ca}_{5}\left(\mathrm{PO}_{4}\right)_{3} \cdot \mathrm{F}$ & $1024,964,866,604,5,565$ & {$[10]$} \\
\hline Дентин мамонт (полированный) & $1036,964,880,605,566$ & {$[27,28]$} \\
\hline $\mathrm{CaSO}_{4} \cdot 2 \mathrm{H}_{2} \mathrm{O}$ & $1146,665,596,452$ & {$[10]$} \\
\hline
\end{tabular}

Примечание.MNS-магнитные наночастицы, диаметр 13-19 nm, ИК спектр дентина получен от механически обработанного бивня мамонта.

предположить, что гипс использовался древним человеком для раскрашивания в качестве белого пигмента и для грунтовки обработанной поверхности перед ее раскраской. Упоминание о наличии гипса в окрашенных артефактах, найденных при раскопках древних культур более поздних эпох, прослеживается в ряде работ, выполненных с помощью современных физических методов [31-44].

На рис. 5 проведено сравнение ИК спектра зоны 1 со спектрами основных пигментов, содержащих окислы железа (кривая 3) и марганца (кривая 4). Для окислов $\mathrm{Fe}$ разной валентности характеристические ИК полосы находятся в диапазоне $800-400 \mathrm{~cm}^{-1}$ (таблица), где поглощение консервационной пленки ПММА весьма слабое, что облегчает анализ ИК полос этого диапазона частот для зон 1 и 2. Основные полосы 540 (плечо) и $440 \mathrm{~cm}^{-1}$ (рис. 5, кривая 1) относятся к колебанию связи $\mathrm{Fe}-\mathrm{O}$ минерала $\alpha-\mathrm{Fe}_{2} \mathrm{O}_{3}$ (Hematite, пигмент красная охра) [10]. Полосы $628,593,445 \mathrm{~cm}^{-1}$ относятся к колебанию связи $\mathrm{Fe}-\mathrm{O}$ минерала $\mathrm{Fe}_{3} \mathrm{O}_{4}$ (magnetite) [45] (таблица). Полоса $630 \mathrm{~cm}^{-1}$ также может принадлежать к модификации окисла $\gamma-\mathrm{Fe}_{2} \mathrm{O}_{3}$ (maghemite) [20].

Полосы в диапазоне $650-750 \mathrm{~cm}^{-1}$ относятся к окислам железа разной валентности и смешанным ионзамещенным соединениям типа $(\mathrm{Me}) \mathrm{PO}_{4}$ и $(\mathrm{Me}) \mathrm{SO}_{4}$, где $\mathrm{Me}=\mathrm{Fe}^{+}, \mathrm{Mn}^{+}, \mathrm{Li}^{+}, \mathrm{Co}^{+}, \mathrm{Ni}^{+}, \mathrm{Cu}^{+}$. Процесс замещения ионов в процессе диффузионного обмена характерен для приграничных слоев веществ, находящихся в длительном контакте с таким материалом, как дентин, состоящим по преимуществу из апатита. При определенных условиях(влажность, температура) ион $\mathrm{Ca}^{+}$ апатита может замещаться на ион $\mathrm{Fe}^{+}$. В результате образуются соединения типа $\mathrm{FePO}_{4}, \mathrm{FePO}_{4} \cdot 2 \mathrm{H}_{2} \mathrm{O}$ [46] или более сложного состава типа $\mathrm{MeFePO}_{4}$ (таблица). В присутствии гипса или ангидрита-безводный сульфат кальция $\left(\mathrm{CaSO}_{4}\right)$ образуются соединения типа $\mathrm{FeSO}_{4}$, $\mathrm{FeSO}_{4} \cdot 2 \mathrm{H}_{2} \mathrm{O}$, при этом многие ИК полосы этих соединений относительно широкие и слабо различаются по частоте. Например, ИК спектр $\mathrm{FePO}_{4}$ (таблица) имеет основные частоты в диапазоне $700-570 \mathrm{~cm}^{-1}$, а соединение $\mathrm{NaFePO}_{4}$ имеет частоты в этом же диапа- 
зоне $700-530 \mathrm{~cm}^{-1}$ [47]. Таким образом, в окрашенном поверхностном слое зоны 1 верхнепалеолитической статуэтки, состоящем из глинозема, гипса и пигментов из окислов $\mathrm{Fe}_{2} \mathrm{O}_{3}$ и $\mathrm{Fe}_{3} \mathrm{O}_{4}$, может за счет химического взаимодействия с дентином образовываться широкий спектр соединений с участием ионов $\mathrm{Fe}^{+}$с переменной валентностью на основе сложных композитов, включающих в свой состав группы $\mathrm{PO}_{4}$ и $\mathrm{SO}_{4}$. Образование такого рода соединений типа ferric phosphates $\mathrm{FePO}_{4} \cdot \mathrm{X} \cdot \mathrm{H}_{2} \mathrm{O}$, где $\mathrm{X}-$ число молекул воды и ferric sulfates $\mathrm{FeSO}_{4} \cdot \mathrm{X} \cdot \mathrm{H}_{2} \mathrm{O}$ приводит к дополнительному уширению полосы $1100 \mathrm{~cm}^{-1}$ группы $\mathrm{O}-\mathrm{Si}-\mathrm{O}$ (например, $\mathrm{FeSO}_{4} \cdot 2 \mathrm{H}_{2} \mathrm{O}$ имеет полосы 1184, 1136 и $1049 \mathrm{~cm}^{-1}$ ) [45]. Другие аморфные hydro ferric sulfates обнаруживают сильную зависимость ширины полосы $1100 \mathrm{~cm}^{-1}$ от содержания в их структуре числа молекул $\mathrm{H}_{2} \mathrm{O}$ [44-51]. Образование таких соединений (таблица), названных в [41] „unspecific iron oxides“, приводит к уширению основных ИК полос и появлению дополнительных. Следует отметить, что положение и интенсивность полос оксидов Fе изменяются в зависимости от кристалличности, размера частиц, формы и частичного замещения иона $\mathrm{Fe}^{+}$другими ионами [40-45]. Краски на основе пигментов, содержащих $\mathrm{Fe}$, обычно включают в свой состав различные компоненты (гипс, кальцит, каолин, кварц и другие силикатные минералы) [33-36], и если содержание этих компонентов высокое, они зачастую маскируют ИК полосы пигмента. Следует дополнительно отметить, что темно-вишневый цвет также имеют артефакты из бивня мамонта в виде фигурок летящих лебедей, найденные в Восточной Сибири (возраст примерно 25-23 тысячи лет), в ИК спектре которых очень четко видны полосы 594 и $538 \mathrm{~cm}^{-1}$, что указывает на наличие в составе поверхности этих объектов окислов $\mathrm{Fe}_{2} \mathrm{O}_{3}$ и $\mathrm{Fe}_{3} \mathrm{O}_{4}$.

При сравнении ИК спектров для зон 1 и 2 (рис. 4) можно заметить не только сильное сужение полосы $\mathrm{O}-\mathrm{Si}-\mathrm{O}$ у $1100 \mathrm{~cm}^{-1}$ для зоны 2, а также сильное уменьшение по сравнению с зоной 1 интенсивности полос 528 и $594 \mathrm{~cm}^{-1}$, положение которых совпадает с наиболее интенсивными полосами окислов $\mathrm{Fe}$ и $\mathrm{Mn}$ в форме наночастиц [44-48]. Это наряду с белым цветом зоны 2 указывает на отсутствие в этой зоне пигментов на основе окислов Fе. Интенсивные полосы 644 и $626 \mathrm{~cm}^{-1}$ в спектрах для зон 1 и 2 принадлежат деформационным колебаниям группы $\mathrm{O}-\mathrm{S}-\mathrm{O}$ аморфной формы гипса (ангидрит), для которой характерна слабая интенсивность полос $\mathrm{H}_{2} \mathrm{O}$. Существенно, что зона 1 имеет весьма плотный относительно толстый слой $d_{2}$, содержащий пигмент. У зоны 2 такой слой заметно тоньше и пигмент отсутствует. Спектр зоны 2 образован высокодисперсным гипсом (глинозем и пигменты отсутствуют), частично заполняющим впадины шероховатой поверхности. Состав зоны 1 образован смесью глинозем-гипс и сложным по химическому составу поверхностным слоем с темно-вишневой окраской, в котором присутствуют преимущественно окислы Fе переменной валентности и группы типа $(\mathrm{Me}) \mathrm{PO}_{4}$. Таким образом, обнаружение гипса в зоне 1 поверхности статуэтки показывает, что его наличие связано с деятельностью древнего человека. С учетом коэффициентов экстинкции основной абсорбционной полосы $1117 \mathrm{~cm}^{-1}$ гипса (рис. 4) для зоны 2 можно вычислить эффективную толщину пленки гипса, которая на основе такой оценки составляет величину порядка нескольких микрон.

В заключение следует отметить, что оценка относительного содержания окислов $\mathrm{Fe}$ и $\mathrm{Mn}$ в поверхностном слое окрашенной зоны 1 женской статуэтки указывает на преобладание пигмента Hematite $\left(\mathrm{Fe}_{2} \mathrm{O}_{3}\right)$, что coгласуется с темно-вишневой окраской зоны $1[4,33,44]$. Тогда как наличие окислов Mn в составе пигмента в поверхностном слое зоны 1 должно бы придавать этому слою черную окраску $[4,34,50]$. Сделанные выводы по преимущественному содержанию окислов железа в составе краски исследованной статуэтки косвенно подтверждаются данными по распределению месторождений марганца и гипса в регионах России. Месторождения марганца в европейской части России имеются только на Урале, тогда как месторождения железа и гипса широко распространены. Достаточно, например, отметить, что в России зарегистрированы 86 промышленных месторождений гипсового сырья.

Вместе с тем окончательное суждение по затронутом вопросу, связанному с использованием древним человеком на территории России черных пигментов на основе марганца, может быть сделано путем привлечения дополнительных независимых методов рентгеновского флуоресценного анализа и порошковой рентгеновской дифрактометрии, которые обеспечивают анализ элементного состава краски.

\section{Финансирование работы}

Работа выполнена в рамках гранта РФФИ № 18-0940043_Древности.

\section{Конфликт интересов}

Авторы заявляют, что у них нет конфликта интересов.

\section{Список литературы}

[1] Leroi-Gourhan Arl., Allaain J. Lascaux inconnu. Paris, 1979.

[2] Menu M., Walter Ph., Vigears D., Clottes J. // Bulletin de la société préhistorique Française. 1993. V. 90. N 6. P. 426-432.

[3] Buisson D., Menu M., Pinçon G., Walter Ph. // Bulletin de la société préhistorique Française. 1989. V. 86. N 6. P. 183-191.

[4] Праслов Н.Д. // Краткие сообщ. ин-та археологии. 1992. B. 206. C. $95-101$.

[5] Ефименко П.П. Костенки І. М., Л.: Изд. АН СССР, 1958. $452 \mathrm{c}$.

[6] Gvozdover M.D. 1995: Art of the Mammoth Hunters: The Finds from Avdeevo (Oxbow Monograph 49). Oxford.

[7] Хлопачев Г.А. (отв. редактор). Верхний палеолит. Образы, символы, знаки. Каталог предметов искусства малых форм из археологического собрания МАЭ РАН. СПб, 2016. 
[8] http://www.kunstkamera.ru/lib/rubrikator/08/08_02/5-88431126-6/

[9] Кирьянов А.В. Реставрация археологических предметов. М.: Изд-во АН СССР, 1960. 96 с.

[10] RRUFF Database Raman, X-ray, Infrared, and Chemistry files. Электронный ресурс. Режим доступа: http://www.rruff.info

[11] Vahur S., Teearu A., Peets P., Joosu L., Leito I. // Analyt. Bioanalyt. Chem. 2016. V. 408. N 13. P. 3373-3379. doi 10.1007/s00216-016-9411-5

[12] Baldridge A.M., Hook S.J., Grove C.I., Rivera G. // Remote Sensing of Environment. 2009. V. 113. P. 711-715.

[13] Ostrooumov M., Lasnier B., Lefrant S. Database: Infrared reflection spectrometry of minerals and gems. Catalogue of the spectrum. Nantes. 1993-2009. Электронный ресурс. Режим доступа: http://www.mineralog.net/?page_id=10

[14] Acquarelli J., van Laarhoven T., Gerretzen J. // Analyt. Chim. Acta. 2017. V. 954. P. 22-31.

[15] Liu H., Liu S., Zhang Z., Sun J., Shu J. // Appl. Optics. 2014. V. 53. P. $8240-8248$.

[16] Liu H., Zhang Z., Liu S. // Appl. Spectr. 2015. V. 69. P. 1013-1022.

[17] Yan Luxin, H. Liu, Chen Liqun, Fang Houzhang, Chang Yi, Zhang Tianxu // J. Mod. Opt. 2013. V. 60. P. 970-982.

[18] Infrared and Raman Spectroscopies of Clay Minerals / Ed. by Gates W.J., Kloprogge T., Madejova J., Bergaya F. V. 8. 2017. $620 \mathrm{p}$.

[19] Золотарев В.М., Никоноров Н.В. Оптические методы исследования материалов фотоники. LAP Lambert Acad. Publ., 2018. 479 c.

[20] Glotch D.T., Rossman G.R. // Icarus. 2009. V. 204. P. 663-671.

[21] Balasubramaniam R., Ramesh Kumar A.V., Dillmann P. // Curr. Sci. 2003. V. 85. N 11. P. 1546-1555.

[22] Li Ying-Sing, Charch J.F., Woodhead A.L. // J. Magn. Magn. Mater. 2012. V. 324. N 8. P. 1543-1550.

[23] Potter R.M., Rossman G.R. // Amer. Mineralogist. 1979. V. 64. P. 1199-1218.

[24] Thomas M., George K.C. // Ind. J. Pure Appl. Phys. 2010. V. 48. P. $104-109$.

[25] Handbook of Optical Constants of Solids / Ed. by Palik E.D. San Diego: Acad. Press, 1985.

[26] Золотарев В.М., Хлопачев Г.А. // Опт. и спектр. 2013. T. 114. № 4. C. 134-148.

[27] Zolotarev V.M., Khlopachev G.A. // Glob. J. Arch. Anthropol. 2018. V. 7. P. 555719.

[28] Золотарев В.М. // Опт. и спектр. 2014. Т. 116. № 4. C. $645-660$.

[29] Дехант Н., Дани, Р., Киммер В., Шмольке Р. Инфракрасная спектроскопия полимеров. М.: Химия, 1976. 472 с.

[30] Золотарев В.М., Волчек Б.З., Власова Е.Н. // Опт. и спектр. 2006. T. 101. № 5. C. 763-770.

[31] Legan L., Leskovar T., Črešnar M., Cavalli F., Innocenti D., Ropretae P. // J. Cult. Her. 2019. https://doi.org/10.1016/j.culher.2019.07.006

[32] Miliani C., Rosi F., Daveri A., Brunetti B.G. // Appl.Phys. A. 2012. V. 106. N 2. P. 295-307.

[33] Siddall Ruth // Minerals. 2018. V. 8. N 201. P. 2-35. doi 10.3390/min 8050201

[34] Gettens R.J., Stout G.L.. Painting Materials: A Short Encyclopedia, Courier Corporation, 2012, 368 p.
[35] Poliszuk A., Ybarra G. // Infrared Spectroscopy: Theory, Developments and Applications / Ed. by Cozzolino D. Nova Science Publishers, P. 519-536.

[36] Ploeger R., Chiantore O., Scalarone D., Poli T. // Appl. Spectr. 2011. V. 65. N 4. P. 429-435.

[37] Reddy et al. // J. Laser Opt. Photonics. 2015. N 2. P. 2-5.

[38] Clottes J. What Is Paleolithic Art?: Cave Paintings and the Dawn of Human Creativity. Pasta blanda, 2016. 208 p.

[39] Mazzocchin G.A., Agnoli F., Colpo I. // Analyt. Chim. Acta. 2003. V. 478. P. $147-161$.

[40] Srividhya J. Iyengar, Mathew Joy, Chandan Kumar Ghosh et al. // RSC Adv. 2014. V. 4. P. 64919-64929. doi $10.1039 / \mathrm{c} 4 \mathrm{ra} 11283 \mathrm{k}$

[41] Roldán García C., Villaverde Bonilla V., Ródenas Marín I., Murcia Mascarós S. // PLoS One. 2016. V. 11. P. e0163565. doi 10.1371/journal.pone.016356

[42] Rifkina R.F., Prinsloob L.C., Dayet L. et al. // J. Arch. Sci. 2016. Rep. 5. P. 336-347.

[43] Mehdi Forouzani // World J. Org. Chem. 2016. V. 4. P. 1-7. doi 10.12691/wjoc-4-1-1

[44] Gotic M., Music S. // J. Mol. Struct. 2007. V. 834-836. P. 445-453. doi 10.1016/j.molstruc.2006.10.059

[45] Jensen B., Rogers A.D., Reeder R.J. // 45th Lunar and Planetary Sci. Confer. 2014. P. 2709.

[46] Zaghib K., Julien C.M. // J. Power Sourc. 2005. V. 142. N 1-2. P. 279-284. doi org/10.1016/j.jpowsour.2004.09.042

[47] Barpanda P., Murugesan C., Lochab S., Baskar S. // ChemCatChem. 2017. V. 10. doi 10.1002/cctc.201701423

[48] Majzlan J. et al. // Chem. Geology. 2011. V. 284. P. 296-305.

[49] Wang, Hong-En et al. // Nanotechnology. 2007. V. 18. P. 115616. doi 10.1088/0957-4484/18/11/115616TY

[50] Pugazhvadivu K.S., Ramachandran K., Tamilarasan K. // Physics Procedia. 2013. V. 49. P. 205-216. doi 10.1016/j.phpro.2013.10.028

[51] National Institute of Standards and Technology (NIST). Электронный ресурс. Режим доступа: https://webbook.nist.g 